08.3

\title{
Нелегированный высокоомный буферный слой GaN для HEMT AIGaN/GaN
}

\author{
(C) Т.В. Малин ${ }^{1}$, Д.С. Милахин ${ }^{1}$, И.А. Александров ${ }^{1}$, В.Е. Земляков ${ }^{2}$, В.И. Егоркин ${ }^{2}$, А.А. Зайцев ${ }^{2}$, \\ Д.Ю. Протасов ${ }^{1,3}$, А.С. Кожухов ${ }^{1}$, Б.Я. Бер ${ }^{4}$, Д.Ю. Казанцев ${ }^{4}$, В.Г. Мансуров ${ }^{1}$, К.С. Журавлёв ${ }^{1,5}$ \\ ${ }^{1}$ Институт фризики полупроводников им. А.В. Ржанова СО РАН, Новосибирск, Россия \\ ${ }^{2}$ Национальный исследовательский университет „МИЭТ“, Зеленоград, Москва, Россия \\ ${ }^{3}$ Новосибирский государственный технический университет, Новосибирск, Россия \\ ${ }^{4}$ Физико-технический институт им. А.Ф. Иофффе РАН, Санкт-Петербург, Россия \\ ${ }^{5}$ Новосибирский государственный университет, Новосибирск, Россия \\ E-mail: mal-tv@isp.nsc.ru
}

Поступило в Редакцию 19 апреля 2019г.

В окончательной редакции 24 апреля 2019 г.

Принято к публикации 24 апреля 2019г.

\begin{abstract}
Продемонстрирована возможность получения методом аммиачной молекулярно-лучевой эпитаксии намеренно нелегированных высокоомных буферных слоев $\mathrm{GaN}$ в AlGaN/GaN-гетероструктурах с высокой подвижностью электронов для транзисторов. Оптимизация ростовых условий $\mathrm{GaN}$ проведена на основании расчетов концентраций фоновых примесей и точечных дефектов для различных соотношений потоков галлия и аммиака.
\end{abstract}

Ключевые слова: GaN, собственные точечные дефекты, фоновые примеси, AlGaN/GaN, HEMT, NH

DOI: 10.21883/PJTF.2019.15.48081.17844

Одной из наиболее важных задач при выращивании гетероструктур для транзисторов с высокой подвижностью электронов (НЕМТ) на основе соединений AIII-N является получение буферного слоя $\mathrm{GaN}$ c высокими значениями пробивного напряжения. Как известно, слои $\mathrm{GaN}$ зачастую имеют $n$-тип проводимости из-за непреднамеренного легирования кислородом из остаточной атмосферы ростовой камеры в процессе роста слоев [1]. Существует два подхода к решению данной задачи. Первый заключается в преднамеренной компенсации доноров акцепторами (углеродом или железом) [2,3]. Второй подход, часто реализуемый в технологии газофазной эпитаксии из металлоорганических соединений (MOCVD), основан на преднамеренном снижении структурного совершенства начальных буферных слоев $\mathrm{GaN}$, в результате чего происходит увеличение количества краевых дислокаций в слоях $\mathrm{GaN}$. Это приводит к возрастанию числа глубоких акцепторных уровней [4], на которые происходит захват электронов с донорных уровней. При легировании буферных слоев $\mathrm{GaN}$ железом наблюдается ,эффект памяти“ [5], что может приводить к непреднамеренному легированию всех слоев гетероструктуры. Целенаправленное снижение структурного совершенства буферных слоев $\mathrm{GaN}$ является противоречивым способом решения проблемы, поскольку повышение плотности дислокаций неизбежно ведет к ухудшению электрофизических параметров двумерного электронного газа. В [3] сообщается о технической возможности использования в технологии MOCVD пропана для легирования слоев GaN углеродом, однако авторы работы установили негативное влияние пропана на структурное совершенство слоев на начальных этапах роста. В ряде работ сообщается о возможности управления фоновым легированием углеродом [6] и кислородом [7] путем изменения ростовых условий.

В настоящей работе продемонстрирована возможность получения методом аммиачной молекулярнолучевой эпитаксии $\left(\mathrm{NH}_{3}-\mathrm{MBE}\right)$ намеренно нелегированных высокоомных слоев $\mathrm{GaN}$ для НЕМТ путем оптимизации ростовых условий на основании расчетов концентраций фоновых примесей для различных соотношений потоков галлия и аммиака.

Расчеты энергий формирования и концентраций точечных дефектов в $\mathrm{GaN}$ проводились методами теории функционала плотности в приближении обобщенного градиента с использованием функционала PBE [8] и оптимизированных сохраняющих норму псевдопотенциалов Вандербита [9] в пакете программ Quantum Espresso. Энергии формирования дефектов рассчитывались с использованием 96-атомной сверхъячейки и сетки $2 \times 2 \times 2$ при интегрировании по зоне Бриллюэна. Энергии формирования дефектов рассчитывались следующим образом [10]:

$$
E_{\text {form }}^{\text {def }}(q)=E_{\text {tot }}^{\text {def }}(q)-E_{\text {tot }}^{\mathrm{GaN}}-\sum_{i} n_{i} \mu_{i}+q\left(E_{\mathrm{F}}+E_{V}\right),
$$

где $E_{\text {form }}^{\text {def }}(q)$ - энергия формирования дефекта в зарядовом состоянии $q, E_{t o t}^{d e f}(q)-$ полная энергия сверхъячейки с дефектом, $E_{t o t}^{\mathrm{GaN}}$-полная энергия сверхъячейки бездефектного $\mathrm{GaN}, n_{i}$ - количество атомов $i$-го элемента, добавленных $\left(n_{i}>0\right)$ или удаленных $\left(n_{i}<0\right)$ из 

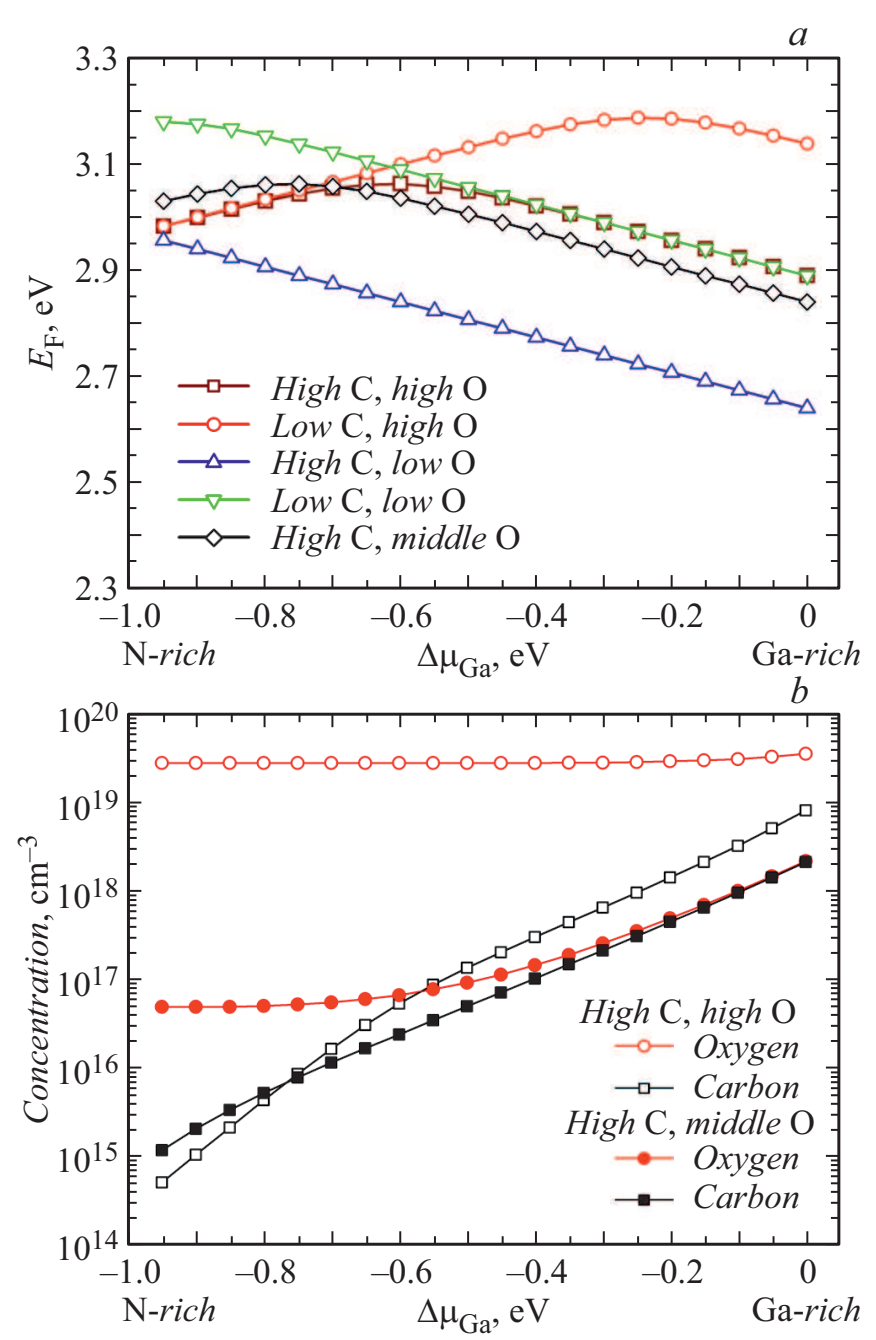

Рис. 1. $a-$ расчет положения уровня Ферми в $\mathrm{GaN}$ в зависимости от химического потенциала галлия для различных уровней легирования $\mathrm{GaN}$ фоновыми примесями кислорода и углерода при температуре роста $800^{\circ} \mathrm{C} ; b-$ расчетные зависимости общей концентрации фоновых примесей кислорода и углерода от химического потенциала галлия при температуре роста $800^{\circ} \mathrm{C}$.

сверхъячейки с дефектом, $\mu_{i}-$ химический потенциал соответствуюшего элемента, $E_{V}$ - край валентной зоны $\mathrm{GaN}, E_{\mathrm{F}}$ - уровень Ферми, отсчитанный от края валентной зоны $\mathrm{GaN}$. Химические потенциалы элементов зависят от ростовых условий. Граничные значения химических потенциалов определяются формированием соответствующих конкурирующих фаз. Например, для Ga-обогащенных условий роста химический потенциал галлия равен полной энергии атома Ga в металлическом $\mathrm{Ga}$, для N-обогащенных условий роста химический потенциал азота равен полной энергии атома $\mathrm{N}$ в молекуле $\mathrm{N}_{2}$. Для примесей углерода и кислорода соответствующими конкурирующими фазами являются углерод в фазе графита или алмаза и $\mathrm{Ga}_{2} \mathrm{O}_{3}$. Концентрации дефектов рассчитывались в предположении, что условия роста близки к термодинамическому равновесию [10]:

$$
c=N_{\text {sites }} N_{\text {config }} \exp \left(-E_{\text {form }} / k T\right)
$$

где $N_{\text {sites }}$ - количество возможных положений дефекта в решетке на единицу объема, $N_{\text {config }}-$ количество возможных конфигураций дефекта. Положение уровня Ферми рассчитывалось из условия зарядовой нейтральности. Расчеты энергий формирования проводились для собственных точечных дефектов и примесей кислорода и углерода. При расчете концентраций учитывалось несколько типов дефектов, имеющих наименьшие энергии формирования: собственные вакансии $V_{\mathrm{Ga}}, V_{\mathrm{N}}$, примеси замещения $\mathrm{C}_{\mathrm{N}}, \mathrm{O}_{\mathrm{N}}$ и комплексы $V_{\mathrm{Ga}} \mathrm{O}_{\mathrm{N}}, V_{\mathrm{Ga}} 2 \mathrm{O}_{\mathrm{N}}$, $V_{\mathrm{Ga}} 3 \mathrm{O}_{\mathrm{N}}, \mathrm{C}_{\mathrm{N}} \mathrm{O}_{\mathrm{N}}$.

На рис. 1, $а$ показаны расчетные зависимости уровня Ферми от химического потенциала галлия при различных химических потенциалах фоновых примесей кислорода и углерода. При увеличении отношения потока $\mathrm{Ga}$ к потоку $\mathrm{NH}_{3}$ концентрация вакансионно-кислородных комплексов уменьшается, а концентрация $\mathrm{O}_{\mathrm{N}}$ растет, что приводит к смещению уровня Ферми ближе к зоне проводимости, однако с некоторого момента уровень Ферми начинает смещаться дальше от зоны проводимости из-за компенсации доноров $\mathrm{O}_{\mathrm{N}}$ акцепторами $\mathrm{C}_{\mathrm{N}}$. При этом растут общие концентрации примесей кислорода и углерода (рис. 1,b). Согласно расчетам, существуют ростовые условия, при которых слои $\mathrm{GaN}$ могут обладать высоким сопротивлением и при этом довольно низкой концентрацией дефектов.

Эпитаксиальные слои $\mathrm{GaN}$ и гетероэпитаксиальная структура (ГЭС) $\mathrm{AlGaN} / \mathrm{GaN}$ с двумерным электронным газом выращивались на подложке $\mathrm{Al}_{2} \mathrm{O}_{3}$ методом $\mathrm{NH}_{3}$-МВЕ. Подложка $\mathrm{Al}_{2} \mathrm{O}_{3}$ нитридизовалась в потоке аммиака $25 \mathrm{sccm}$ в течение $10 \mathrm{~min}$ при температуре $840^{\circ} \mathrm{C}$. Данные условия нитридизации приводят к росту

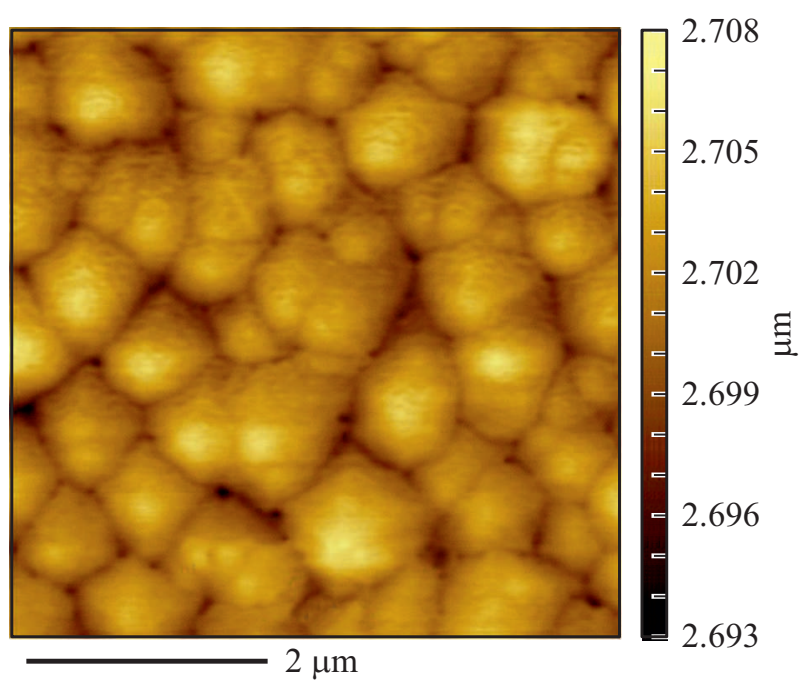

Рис. 2. Изображение поверхности слоя $\mathrm{GaN}$ размером $5 \times 5 \mu \mathrm{m}$, полученное с помощью атомно-силового микроскопа, $Z$-шкала $-15 \mathrm{~nm}, \mathrm{RMS}=2 \mathrm{~nm}$. 

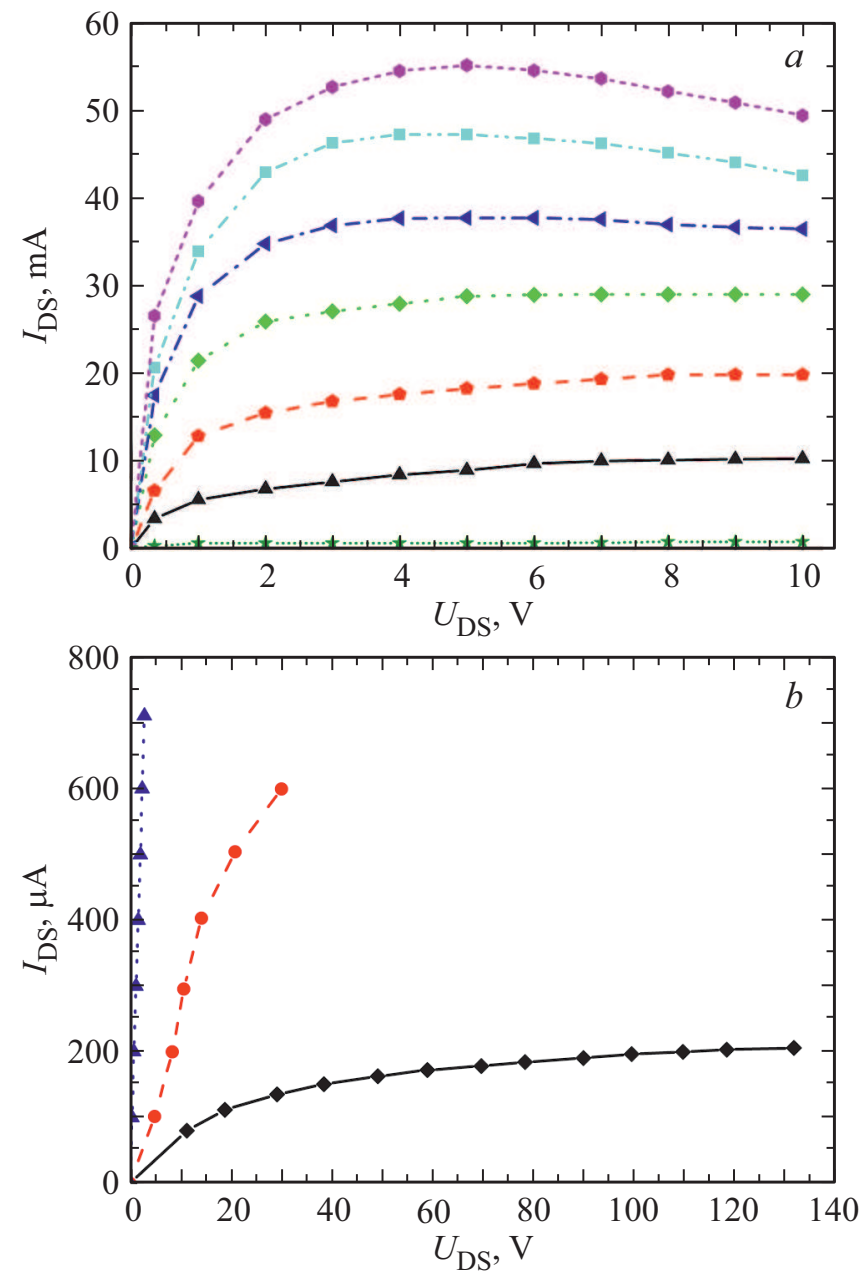

Рис. 3. $a-$ вольт-амперные характеристики тестового транзистора, напряжение на затворе изменялось от 0 до $-3 \mathrm{~V}$ с шагом $0.5 \mathrm{~V}$ на ступеньку; $b$ - измерение тока утечки закрытого транзистора, напряжение на затворе изменялось от -4 до $-5 \mathrm{~V}$ с шагом $0.5 \mathrm{~V}$ на ступеньку.

AlN металлической полярности [11]. Далее выращивался буферный слой AIN металлической полярности толщиной $300 \mathrm{~nm}$, затем слой $\mathrm{GaN}$ толщиной $1000 \mathrm{~nm}$. В тех же ростовых условиях, что и $\mathrm{GaN}$, выращивались модификатор квантовой ямы AlN толщиной $1 \mathrm{~nm}$, барьерный слой $\mathrm{AlGaN}$ толщиной $25 \mathrm{~nm}$, верхние $15 \mathrm{~nm}$ которого были легированы $\mathrm{Si}$, и защищающий от окисления „сар“-слой $\mathrm{GaN}$ толщиной $2 \mathrm{~nm}$. Для реализации стехиометрических условий, способствующих формированию слоев $\mathrm{GaN}$ с высоким сопротивлением, была выбрана температура роста $800^{\circ} \mathrm{C}$ при потоке аммиака $200 \mathrm{sccm}$. Столь низкая температура роста позволяет снизить вхождение кислорода в $\mathrm{GaN}$ в процессе роста, что приводит к формированию самокомпенсированного материала, и одновременно является достаточной для обеспечения гладкой морфологии поверхности слоев $\mathrm{GaN}$ со среднеквадратичной шероховатостью $\mathrm{RMS}=2 \mathrm{~nm}$ (рис. 2).
Исследование буферных слоев $\mathrm{GaN}$ методом вторично-ионной масс-спектрометрии (ВИМС) позволило установить характерные уровни легирования фоновыми примесями кислорода $N_{\mathrm{O}}=1.5 \cdot 10^{17} \mathrm{~cm}^{-3}$ и углерода $N_{\mathrm{C}}=2.4 \cdot 10^{17} \mathrm{~cm}^{-3}$. Сопоставление результатов расчетов концентраций углерода и кислорода в слое $\mathrm{GaN}$ с результатами профилей ВИМС позволяет оценить концентрацию свободных электронов в слое $\mathrm{GaN}$ $n=8.0 \cdot 10^{9} \mathrm{~cm}^{-3}$, что соответствует удельному сопротивлению слоя $\rho=2.1 \cdot 10^{11} \Omega / \mathrm{sq}$.

Для изготовления тестовых транзисторов использовалась ГЭС с буферным слоем $\mathrm{GaN}$, выращенным согласно выбранным ростовым условиям. Концентрация $n=1.0 \cdot 10^{13} \mathrm{~cm}^{-2}$ и подвижность электронов $\mu=1650 \mathrm{~cm}^{2} /(\mathrm{V} \cdot \mathrm{s})$ в ГЭС были измерены с помощью эффекта Холла. Омические контакты полевых транзисторов формировались оптической литографией на основе металлизации $\mathrm{Ti} / \mathrm{Al} / \mathrm{Ni} / \mathrm{Au}$, а затвор Шоттки длиной $0.25 \mu \mathrm{m}$ - электронной литографией. Вольт-амперные характеристики транзисторов с шириной затвора $90 \mu \mathrm{m}$ приведены на рис. 3, $a$. Удельная крутизна транзистора составила $250 \mathrm{mS} / \mathrm{mm}$. Измеренный ток утечки закрытого транзистора при подаче запирающего напряжения $-5 \mathrm{~V}$ и напряжении сток-исток $U_{\mathrm{DS}}=135 \mathrm{~V}$ составил $\sim 220 \mu \mathrm{A}$ (рис. $3, b)$, что, с одной стороны, открывает возможность работы транзистора при напряжении на стоке до $70 \mathrm{~V}$, а с другой - резко повышает надежность при работе на стандартном для СВЧ-приложений напряжении $U_{\mathrm{DS}}=28 \mathrm{~V}$. Коэффициент усиления по мощности на частоте $3 \mathrm{GHz}$ составил более $14 \mathrm{~dB}$, удельная плотность импульсной мощности более $3 \mathrm{~W} / \mathrm{mm}$. Утечки по буферу, измеренные после ионной изоляции, составили менее $1 \mu \mathrm{A}$ по уровню $400 \mathrm{~V}$ на зазоре в $5 \mu \mathrm{m}$.

Таким образом, в работе продемонстрирована возможность синтеза методом $\mathrm{NH}_{3}$-MBE высокоомных буферных слоев $\mathrm{GaN}$, что подтверждено малыми токами утечки тестовых транзисторов.

\section{Благодарности}

ВИМС-измерения проводились на оборудовании федерального ЦКП „Материаловедение и диагностика в передовых технологиях“.

\section{Финансирование работы}

Работа выполнена при финансовой поддержке Министерства образования и науки РФ в рамках соглашения № 14.577.21.0250 от 26.09.17, уникальный идентификатор проекта RFMEFI57717X0250.

\section{Конфликт интересов}

Авторы заявляют, что у них нет конфликта интересов. 


\section{Список литературы}

[1] Caliebe M., Scholz F. // Annual Report. Institute of Optoelectronics, Ulm University, 2016. P. 23-28.

[2] Bougrioua Z., Azize M., Jimenez A., Brana A.-F., Lorenzini P., Beaumont B., Munoz E., Gibart P. // Phys. Status Solidi C. 2005. V. 2. N 7. P. 2424-2428.

DOI: $10.1002 /$ pssc. 200461588

[3] Lundin W.V., Sakharov A.V., Zavarin E.E., Kazantsev D.Yu., Ber B.Ya., Yagovkina M.A., Brunkov P.N., Tsatsulnikov A.F. // J. Cryst. Growth. 2016. V. 449. P. 108-113. DOI: $10.1016 /$ j.jcrysgro.2016.06.002

[4] Weimann N.G., Eastman L.F., Doppalapudi D., Ng H.M., Moustakas T.D. // J. Appl. Phys. 1998. V. 83. N 7. P. $3656-$ 3659. DOI: $10.1063 / 1.366585$

[5] Rudziński M., Desmaris V., van Hal P.A., Weyher J.L., Hageman P.R., Dynefors K., Rodle T.C., Jos H.F.F., Zirath H., Larsen P.K. // Phys. Status Solidi C. 2006. V. 3. N 6. P. 22312236. DOI: $10.1002 /$ pssc. 200565379

[6] Gamarra P., Lacam C., Tordjman M., Splettstosser J., Schauwecker B., di Forte-Poisson M.-A. // J. Cryst. Growth. 2015. V. 414. P. 232-236. DOI: $10.1016 /$ j.jcrysgro.2014.10.025

[7] Schubert F., Wirth S., Zimmermann F., Heitmann J., Mikolajick T., Schmult S. // Sci. Technol. Adv. Mater. 2016. V. 17. N 1. P. 239-243.

DOI: $10.1080 / 14686996.2016 .1178565$

[8] Perdew J.P., Burke K., Ernzerhof M. // Phys. Rev. Lett. 1996. V. 77. N 18. P. 3865-3868.

DOI: 10.1103/PhysRevLett.77.3865

[9] Hamann D.R. // Phys. Rev. B. 2013. V. 88. N 8. P. 085117. DOI: 10.1103/PhysRevB.88.085117

[10] Van de Walle C.G., Neugebauer J. // J. Appl. Phys. 2004. V. 95. N 8. P. 3851-3879. DOI: 10.1063/1.1682673

[11] Малин Т.В., Милахин Д.С., Мансуров В.Г., Галищын Ю.Г., Кохуххов А.С., Ратников В.В., Смирнов А.Н., Давыдов В.Ю., Журавлев К.С. // ФТП. 2018. Т. 52. В. 6. С. 643 650. DOI: 10.21883/PJTF.2019.15.48081.17844 